\title{
The role of enzyme replacement therapy in severe Hunter syndrome - an expert panel consensus
}

\author{
Joseph Muenzer • Olaf Bodamer • Barbara Burton • Lorne Clarke • \\ Gudrun Schulze Frenking • Roberto Giugliani • Simon Jones • \\ Maria Verónica Muñoz Rojas • Maurizio Scarpa • Michael Beck • Paul Harmatz
}

Received: 25 July 2011 / Accepted: 7 October 2011 /Published online: 29 October 2011

(C) The Author(s) 2011. This article is published with open access at Springerlink.com

\begin{abstract}
Intravenous enzyme replacement therapy (ERT) with idursulfase for Hunter syndrome has not been demonstrated to and is not predicted to cross the blood-brain barrier. Nearly all published experience with ERT with idursulfase has therefore been in patients without cognitive impairment (attenuated phenotype). Little formal guidance is available on the issues surrounding ERT in cognitively impaired patients with the severe phenotype. An expert panel was therefore convened to provide guidance on these issues. The clinical experience of the panel with 66 patients suggests that somatic improvements (e.g., reduction in liver volume, increased mobility, and reduction in frequency of respiratory infections) may occur in most severe patients. Cognitive benefits have not been seen. It was agreed that, in general, severe patients are candidates for at least a 6-12-month trial of
\end{abstract}

J. Muenzer $(\square)$

Department of Pediatrics, CB 7487, Medical School Wing E

Room 117, University of North Carolina at Chapel Hill,

Chapel Hill, NC 27599-7487, USA

e-mail: muenzer@med.unc.edu

O. Bodamer

Division of Clinical and Translational Genetics,

University of Miami Miller School of Medicine,

Miami, FL, USA

B. Burton

Children's Memorial Hospital and Northwestern University

Feinberg School of Medicine,

Chicago, IL, USA

L. Clarke

Department of Medical Genetics, University of British Columbia,

Vancouver, BC, Canada

G. S. Frenking $\cdot$ M. Beck

Children's Hospital, University of Mainz,

Mainz, Germany
ERT, excluding patients who are severely neurologically impaired, those in a vegetative state, or those who have a condition that may lead to near-term death. It is imperative that the treating physician discuss the goals of treatment, methods of assessment of response, and criteria for discontinuation of treatment with the family before ERT is initiated. Conclusion: The decision to initiate ERT in severe Hunter syndrome should be made by the physician and parents and must be based on realistic expectations of benefits and risks, with the understanding that ERT may be withdrawn in the absence of demonstrable benefits.

Keywords Mucopolysaccharidosis II · Hunter syndrome · Enzyme replacement therapy $\cdot$ Idursulfase $\cdot$ Cognitive impairment $\cdot$ Severe phenotype

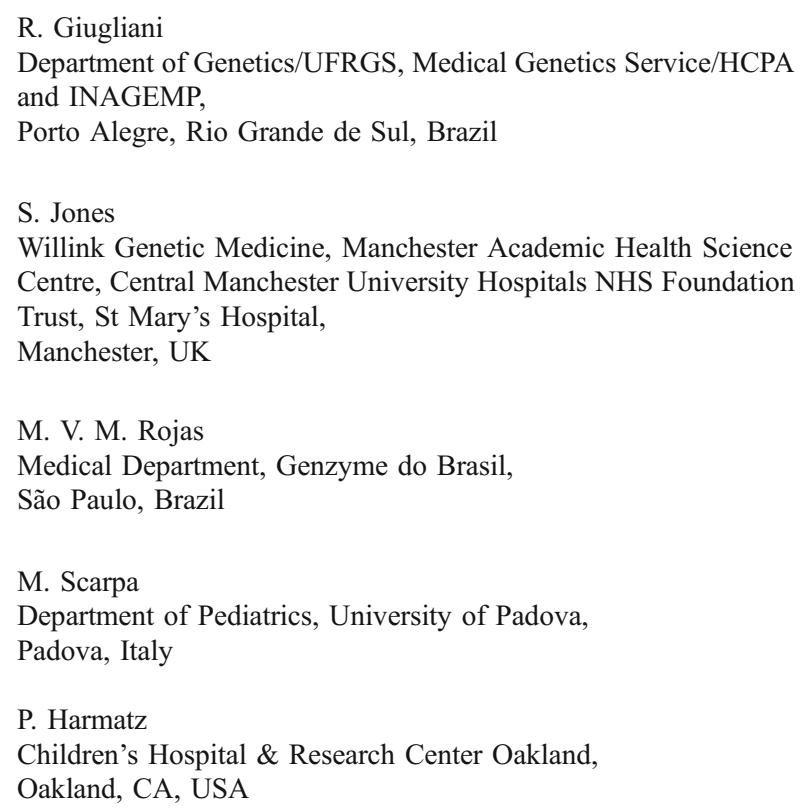




\section{Introduction}

The development of therapies for rare complex diseases, with their associated high price, has raised many questions and concerns related to pharmacoeconomics and societal desires to meet the particular needs of patients with rare diseases. Enzyme replacement therapy (ERT) has become a standard of care for patients with several lysosomal storage disorders [12, 15, 25, 36], but because of disease heterogeneity, particularly in the mucopolysaccharidoses, there is disagreement as to the role that such treatments play for the severely affected patients as well as patients who are at the end stages of disease.

Hunter syndrome (mucopolysaccharidosis II, OMIM 309900) is one of these mucopolysaccharidoses [17] for which a specific, targeted treatment, ERT with idursulfase (Elaprase ${ }^{\circledR}$, Shire Human Genetic Therapies, Inc., Cambridge, MA, USA), has been developed [25]. Approximately two thirds of the patients with this condition will develop progressive neurodegeneration [24], ultimately affecting cognitive function and limiting lifespan. Intravenous administration of ERT does not allow for sufficient enzyme to cross the blood-brain barrier and reach the central nervous system, yet some physicians and families have seen benefits to its use in these severe patients for the improvement or stabilization of some somatic signs and symptoms.

The present manuscript is based on discussions of an international panel of physicians experienced in the management and treatment of patients with Hunter syndrome. This group was convened in mid-2008 by Shire Human Genetic Therapies, Inc. (Cambridge, MA, USA) to discuss issues surrounding the use of idursulfase in Hunter patients with the severe phenotype. This manuscript follows two previous papers on diagnosis and management of Hunter syndrome that were developed in a similar fashion $[17,26]$.

\section{Hunter syndrome overview}

Hunter syndrome (mucopolysaccharidosis II, MPS II) is a rare, X-linked metabolic disease that is caused by a deficiency of the lysosomal enzyme, iduronate-2-sulfatase (I2S) $[1,27]$. This enzyme catalyzes the removal of sulfate at the 2 position of L-iduronic acid present at the nonreducing end of the glycosaminoglycans (GAG) dermatan sulfate and heparan sulfate. In Hunter syndrome patients, these substrates accumulate both intracellularly and extracellularly and, through poorly understood mechanisms, lead to the clinical features of the disease. Over 300 mutations in the gene encoding iduronate-2-sulfatase have been described, many of which represent private or nonrecurrent mutations. There is no evidence of significant disease modifiers, and thus the heterogeneity of the disease phenotype (see below) is believed to be related to the amount and activity of residual enzyme conferred by the mutation. As such, deletions and gene rearrangements, which account for up to $25 \%$ of Hunter syndrome cases, always result in a severe phenotype [10, 13, 16, 22, 32].

\section{General phenotype}

The phenotypic expression of Hunter syndrome has recently been described in detail [17, 37]. MPS II affects multiple organs and systems with a variable age of onset of signs and symptoms and a variable rate of progression. The clinical spectrum of Hunter syndrome spans a wide range, from an attenuated to a severe phenotype [27]. Patients usually appear normal at birth, but in the most severely affected patients, signs and symptoms typically begin to appear between 2 and 4 years of age. All affected patients, including those with an attenuated phenotype, experience progressive somatic involvement, including enlarged liver and spleen, skeletal and joint involvement resulting in reduced joint range of motion and contractures, and heart and airway disease [17, 27, 37]. In addition, patients with the severe phenotype experience profound neurological involvement that results in severe cognitive impairment, progressive neurodegeneration, and death in the second decade of life [17, 41, 42]. Patients with an attenuated phenotype demonstrate normal intelligence and usually survive into adulthood, although shortened life span is seen [40]. The prediction of an attenuated or severe phenotype is difficult early in the course of the disease for many patients.

\section{Severe Hunter syndrome}

Severe Hunter syndrome is the description used to refer to patients who demonstrate progressive central nervous system involvement with early cognitive impairment. It has been estimated that about two thirds of patients are destined to have a severe phenotype [7, 24, 32]. Patients with a severe phenotype typically have an earlier onset of signs and symptoms - age 2 to 4 years - than is seen with the attenuated phenotype [42]. The profound cognitive impairment results in delayed developmental milestones, with an onset in early childhood. Developmental skills plateau between 4 and 6 years of age and decline thereafter. These patients often exhibit severe behavioral problems, including hyperactivity, obstinacy, and aggression, beginning in the second year of life and continuing to late childhood [39]. Behavior may later appear to improve, with a decrease in hyperactivity and aggression, but this change is due to continuing neurodegeneration [39]. Late-stage 
disease is characterized by a neurodegenerative state often associated with seizures and lack of mobility [41]. Communicating hydrocephalus with increased intracranial pressure may contribute to the behavioral problems, as well as seizures [33, 38].

\section{Management and treatment of severe Hunter syndrome}

Historically, the management of Hunter syndrome was directed to the specific disease symptoms and complications, regardless of the phenotype [23, 24]. For example, surgery may be required to relieve respiratory obstruction caused by enlarged tonsils and adenoids. As emphasized in a recent review, the management of Hunter syndrome is never routine, and because of the progressive multisystem involvement, management always requires a multidisciplinary and anticipatory approach [24].

Recombinant human I2S (idursulfase, Elaprase ${ }^{\circledR}$, Shire Human Genetic Therapies, Inc., Cambridge, MA, USA) was approved for the treatment of Hunter syndrome in 2006 and is available in the United States, European Union, and other countries. Idursulfase is administered intravenously on a weekly basis in the hospital setting. Some Hunter syndrome patients have been reported to have received infusions at home; this is only undertaken after a lengthy screening process and is not available in all countries [2-4, $14,21]$. The approval of idursulfase was based on data from the pivotal clinical trial, which demonstrated that 1 year of weekly infusions of $0.5 \mathrm{mg} / \mathrm{kg}$ significantly improved the primary endpoint, a composite comprising changes in distance walked in $6 \mathrm{~min}$ and changes in percentpredicted forced vital capacity (FVC) compared to placebo [25]. Other improvements included reduction in urinary GAG excretion, reduction in liver and spleen volume, and improvements in absolute FVC.

No severely affected patients were included in the pivotal trial because of their inability to perform pulmonary function testing or the 6-min walk test, the two components of the composite end point. Because a significant amount of enzyme has not been demonstrated to and is not predicted to cross the blood-brain barrier, clinical improvement of central neurological involvement in patients with the severe phenotype is not expected. Severely affected patients would be expected to experience somatic improvement with idursulfase treatment, however, but no clinical studies of ERT in severe Hunter patients have been conducted and only a few case reports have been published (e.g., [8, 28]).

Hematopoietic stem cell transplantation (HSCT) has become the treatment of choice for the severe form of mucopolysaccharidosis I (Hurler syndrome), in which successful transplantation can preserve neurocognition, improve some aspects of the somatic disease, and markedly increase survival $[24,36]$. There is little evidence to support the use of HSCT in Hunter syndrome, however. To date, only small case series have been reported. These indicate that HSCT results in stabilization or improvement in some somatic manifestations of Hunter syndrome, as seen with recombinant ERT, but little or no cognitive benefit has been demonstrated [11, 20, 29, 35].

\section{Enzyme replacement therapy in severe Hunter syndrome}

The authors have had experience with the use of idursulfase in 66 Hunter syndrome patients with the severe phenotype. All of these patients, who were 2 to 24 years old, experienced the somatic manifestations of Hunter syndrome and demonstrated variable aspects of cognitive involvement, including loss of speech, behavioral issues, and developmental degeneration. After at least 1 year of ERT, 50 out of 66 patients experienced at least one type of somatic improvement, such as a reduction in the frequency of respiratory infections, a reduction in the coarseness of facial features, improved joint range of motion, or improved sleep apnea. It is the opinion of the authors that the younger patients responded better than older patients. Nearly all of the patients displayed a reduction in liver volume (61 of 66). Improvements in hepatomegaly are clinically relevant in that they may improve overall patient comfort from symptoms such as dyspnea, early satiety, or gastroesophageal reflux. In addition, a sustained reduction in liver volume is a clinical biomarker that can be used to reflect the activity of ERT. Parent-reported- and/or physician-observed improvement in mobility was noted in 35 out of 66 . None of the patients could be described as experiencing a direct effect on cognitive function as a result of ERT. In some cases, an improvement in behavior was noted by the family, but this may have reflected improvements in general health and quality of life resulting from somatic improvements. Thirty-one patients experienced an infusion reaction during treatment, which was managed by slowing or stopping the infusion and pretreatment with an antihistamine and/or corticosteroid prior to subsequent infusions. Sufficient benefit to continue ERT was determined to be present in 61 out of 66 patients. In five cases, the lack of clinical benefit resulted in the decision to withdraw ERT.

\section{Discussion and commentary}

During the meeting of the expert panel, important clinical and ethical issues concerning the use of ERT in severe Hunter patients were discussed. These issues included: (1) 
which patients should be considered candidates for the initiation of ERT, (2) treatment goals, (3) assessing response to ERT, (4) when to discontinue ERT, (5) the development of guidelines about ERT in severe Hunter syndrome, and (6) the role of government and health reimbursement agencies in the determination of eligibility for ERT in severe Hunter syndrome.

\section{Initiation of ERT in severe Hunter syndrome}

The decision to initiate ERT in a patient with severe Hunter syndrome must be made with the disease stage in mind. If the patient is newly diagnosed, they should be offered treatment, even if the rate of cognitive decline or severity of their eventual cognitive phenotype is not yet apparent. Hunter syndrome is a progressive disease that affects multiple systems and results in irreversible organ damage over time. Both patients with attenuated disease (cognitively intact) and those with severe disease (cognitively impaired) experience many somatic signs and symptoms that can reduce quality of life, including hepatosplenomegaly, impaired respiratory function, sleep apnea, frequent infections, and joint pain [17, 27, 37]. Therefore, withholding a therapeutic that has the potential to improve some of the somatic manifestations of the disease because of an eventual cognitive decline is not justifiable in the newly diagnosed patient.

It is the authors' opinion that all previously diagnosed, symptomatic patients in whom there is an expectation that ERT will alter the course of the somatic involvement are also candidates for a trial of idursulfase treatment, even if cognitive impairment is already evident. As with newly diagnosed patients, the somatic signs and symptoms of the disease may reduce the quality of life for both the patient as well as for the caregivers; therefore, a trial of a therapeutic that may improve some of the somatic features is justified. A critical part of the initiation process for both newly diagnosed patients and those who have been previously diagnosed is to discuss treatment goals, the evaluation of response to ERT, and the eventual discontinuation of therapy with the family at the outset (discussed in more detail below).

Not all patients with severe Hunter syndrome should be considered candidates for ERT. It is the opinion of the authors that patients who are severely neurologically impaired (such as in a vegetative state) with subsequent low expectation of benefit should not be considered for ERT. What constitutes severe neurological impairment may be the subject of some debate, but a patient who is gastrostomy fed due to an inability to swallow would likely fall into this category. Similarly, patients who have a disease manifestation or other condition that may lead to near-term death should not receive ERT.

\section{Goals of treatment}

Before beginning ERT, it is absolutely essential that the physician and family discuss the goals of treatment, expectations for response, methods for evaluating response, and criteria for discontinuing therapy. This discussion should ideally be directly between the treating physician and family. It should be emphasized in these discussions that ERT should be considered a trial and that the response to ERT will be evaluated after a minimum of 6 to 12 months. A key point that must be made is that ERT will not alter the course of the neurological decline but may produce somatic improvements, such as improved mobility, reductions in liver and spleen volumes, and reductions in respiratory infections and resultant hospitalizations. A written summary of the discussion may be helpful in managing family expectations and could include the statement that the response to ERT will be evaluated at a certain time point and that ERT may be discontinued if the physician and family agree that no benefit has been demonstrated. In the authors' opinion, a perceived improvement in the quality of life by the family should be taken into strong consideration as a reason to continue therapy even if other clinical benefits are not obvious on examination.

Parents and guardians need to be aware that not all responses may be positive. For example, infusion reactions, which typically involve pyrexia, chills, flushing, and/or headache, would be expected to occur in some patients (as they do in patients with an attenuated phenotype [25]), and the patients would not be able to articulate their symptoms during these events. It was also the experience of several members of the panel that ERT may result in worsening of behavioral problems in some severe Hunter patients.

The importance of a discussion with the family about goals and expectations cannot be understated, as these expectations play a major role in influencing their decision about whether to initiate ERT. This was recently illustrated in a survey study by Coman and colleagues [5]. In their study, 249 parents/caregivers and adult patients with an MPS disorder who were part of MPS support groups in the United States and Australia were surveyed to solicit their opinion of whether to initiate ERT based on a hypothetical phenotype and hypothetical response to ERT. For Hunter syndrome patients with a severe phenotype and with the expectation that ERT would result in minimal physical improvement, no change in cognitive involvement, and a 3year increase in expected life span, $57 \%$ of respondents would choose to use ERT. For the same patients and same expectations, with the exception of a 15 -year increase in lifespan, $79 \%$ of respondents would choose ERT. If cognitive improvement were expected, nearly all would choose ERT. 


\section{Assessment of the response to ERT}

The major challenge in evaluating the response to ERT in severe Hunter patients is the lack of assessment tools that are validated in this population. For example, there is no validated instrument that can objectively measure changes in function and quality of life in cognitively impaired patients with Hunter syndrome, although the development of such an instrument is currently the object of much concerted effort. Additionally, there are no validated biomarkers that can be used to measure response to treatment, although again much research effort is currently directed towards this problem. Some physicians have attempted to use clinical trial endpoints, but these were developed for patients with no cognitive involvement. Patients with cognitive impairment are most often unable to comprehend and cooperate with testing [9]. For example, such patients cannot independently perform the 6-min walk test (6MWT), and the results of a "parent-assisted" 6MWT are not meaningful for evaluating mobility and endurance in severely affected patients and should not be used. Similarly, pulmonary function tests like the ones that were used to demonstrate the clinical efficacy of idursulfase in clinical trials require the understanding and cooperation of the patient and are beyond the capabilities of severely affected patients.

However, certain evaluations are useful in this population. The physician may be able to evaluate joint range-of-motion in the cognitively impaired patient and can note improvements in liver and spleen size, coarseness of facial features, and macroglossia on examination. Frequency of respiratory infections and resulting hospitalizations is another factor that may be quantified. Yet, assessing the response to ERT is for a large part subjective and must, by necessity, be based upon the physician's clinical impression and upon parental assessment. Certainly parents are inherently biased and may see improvement where no objective improvement exists; however, parents can report on objective milestones (e.g., getting out of bed, climbing stairs, improved appetite, etc.). In the authors' opinion, an important goal of therapy is the improvement in quality of life for the patient and family, so a perception by the family of improved quality of life should be taken into strong consideration when deciding whether or not to continue therapy.

\section{Decision to stop ERT in severe Hunter syndrome}

The use of ERT in a patient with severe Hunter syndrome should be considered a trial by both the physician and the family. Goals for treatment should have been discussed before ERT was initiated, with assessment occurring after some agreed upon time period. It is the opinion of most of the authors that 6 to 12 months should be sufficient to determine if clinical benefit is occurring [37]; however, some authors feel that up to 18 months may be needed. Included in these discussions should be the idea that ERT cannot stop the eventual neurological decline and should at some point be discontinued. Although such discussions can be difficult, it is important to convey to families that when a patient is significantly neurologically impaired, such as being gastrostomy fed due to an inability to swallow or in a vegetative state, there is little benefit to continuing with ERT. Similarly, it is the experience of the authors that occasionally a patient with severe Hunter syndrome will display exacerbated behavioral difficulties as a result of therapy; such an occurrence often reduces patient and family quality of life and can be the criterion for discontinuing ERT.

It should be pointed out that, to some families, the goal of ERT is to prolong survival no matter what is the state of the patient. In certain countries (e.g., Germany, UK, and Austria), ERT would currently be continued if the parents insisted, despite the apparent lack of response. In certain provinces of Canada, neurological deterioration and loss of independent functioning could be the basis for discontinuation of treatment. Comprehensive guidelines are needed to help guide these decisions and are currently in development.

\section{Guidelines for ERT in severe Hunter syndrome}

Guidelines for the use of idursulfase in the treatment of Hunter syndrome have been published for Australia [18] and UK [34] and are being developed in other countries and regions. As expected, treatment guidelines will differ among countries. For example, in the UK, all patients with a documented I2S deficiency are eligible to receive idursulfase regardless of phenotype, whereas in Australia only patients with an attenuated phenotype are considered eligible for treatment. The Australian guidelines allow the treatment of young patients before the phenotype can be determined, but stipulate that ERT is to be withdrawn if neurological involvement becomes evident. To date, guidelines specific to treatment of severe Hunter syndrome patients have not been published for any other country.

\section{Role of government and health reimbursement agencies}

The policies of the local health care system may influence the decision about which severe Hunter patients might receive ERT. For example, in the UK all patients with documented I2S deficiency are eligible for ERT, regardless of phenotype [34]. Similarly, in Germany, all patients would be offered treatment (Michael Beck, personal communication). In Canada, the decision about ERT would be made on a case-by-case evaluation and would depend on the level of funding for ERT in the individual provinces. 
For example, in Canada, a predictably severe patient (i.e., has a complete deletion of the gene) under the age of 5 years would likely be treated, but an older patient who presents clear evidence of neurodegeneration would not (Lorne Clarke, personal communication). In the United States, the decisions are made by the individual physicians and the patient's families or guardians. In any situation, it is important that the ultimate decision be made jointly by the physician and the family.

Governments and reimbursement agencies are increasingly using pharmacoeconomic analyses to guide decisions about the use and funding of new drugs or treatments. No cost-effectiveness study of ERT in Hunter syndrome has been published. In the cases of Fabry disease $[6,21]$ and MPS VI [30], traditional analyses based on the cost per quality-adjusted life year have failed to demonstrate costeffectiveness of ERT. The societal and ethical considerations of funding ERT for lysosomal storage diseases have been studied, but no consensus has emerged about methods of funding ERT. It must be understood that these diseases are extremely rare, and although ERT is expensive, the overall cost to a government or reimbursement agency is small compared with their total health care expenditures.

\section{Summary}

The decision regarding the use of ERT in Hunter disease patients with a severe phenotype is complex and based on many considerations, including the clinical status of the patient, the expectation of benefit, and the risks associated with ERT. The authors' clinical experiences in treating severe Hunter patients have been generally positive, but the decision to initiate and possibly stop ERT needs to be individualized based on the considerations noted above.

Proposed Boxed Guidelines

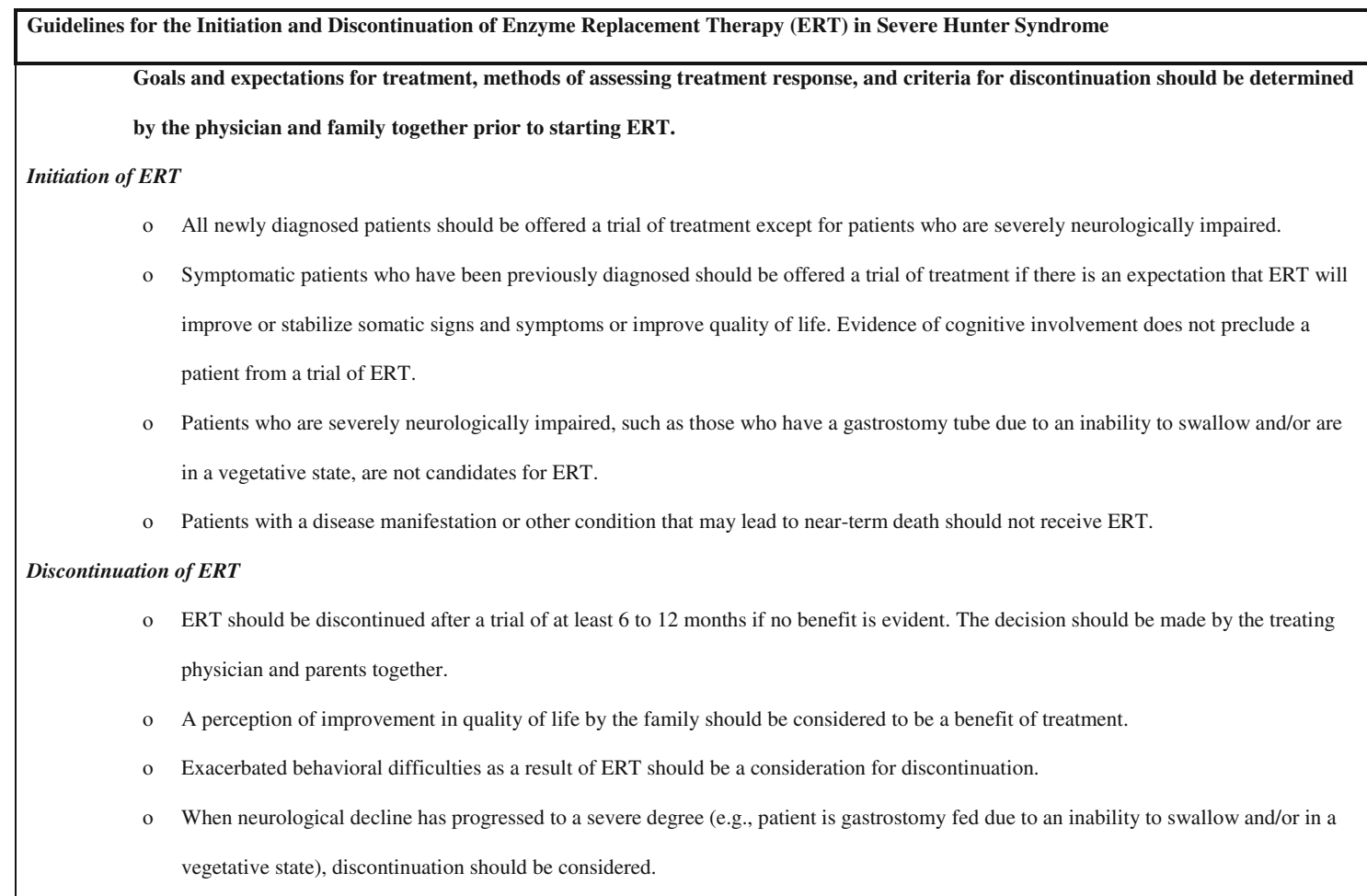

Acknowledgments This manuscript was developed as the result of a Shire HGT-sponsored meeting of experts in the management and treatment of patients with severe Hunter syndrome held in Vancouver, BC, Canada, in June 2008. Shire HGT had no role in the content presented and discussed at the meeting. The authors confirm independence from the funding source. Assistance with data collection was kindly provided by Christina Lampe, M.D., Children's Hospital, University of Mainz, Mainz, Germany. Edito- rial assistance in the development of this manuscript was provided by Edward Weselcouch, Ph.D., of PharmaWrite and Jillian Lokere, M.S., of the Curry Rockefeller Group and was paid for by Shire HGT. Shire HGT reviewed the manuscript only to confirm the accuracy of all statements regarding the pivotal trial of its enzyme replacement therapy, idursulfase. All authors participated in the development and writing of the manuscript and are fully responsible for its content. 
Financial Disclosure Drs. Muenzer, Bodamer, Burton, Clarke, Giugliani, Jones, Muñoz Rojas, Schulze Frenking, Scarpa, Beck, and Harmatz have received honoraria, travel grants, or research grants from Shire Human Genetic Therapies, Inc.

Open Access This article is distributed under the terms of the Creative Commons Attribution Noncommercial License which permits any noncommercial use, distribution, and reproduction in any medium, provided the original author(s) and source are credited.

\section{References}

1. Bach G, Eisenberg F Jr, Cantz M, Neufeld EF (1973) The defect in the Hunter syndrome: deficiency of sulfoiduronate sulfatase. Proc Natl Acad Sci U S A 70:2134-2138

2. Bagewadi S, Roberts J, Mercer J, Jones S, Stephenson J, Wraith JE (2008) Home treatment with Elaprase and Naglazyme is safe in patients with mucopolysaccharidoses types II and VI, respectively. J Inherit Metab Dis 31:733-737

3. Burton BK, Guffon N, Roberts J, van der Ploeg AT, Jones SA, HOS investigators (2010) Home treatment with intravenous enzyme replacement therapy with idursulfase for mucopolysaccharidosis type II-data from the Hunter Outcome Survey. Mol Genet Metab 101:123-129

4. Burton BK, Wiesman C, Paras A, Kim K, Katz R (2009) Home infusion therapy is safe and enhances compliance in patients with mucopolysaccharidoses. Mol Genet Metab 97:234-236

5. Coman DJ, Hayes IM, Collins V, Sahhar M, Wraith JE, Delatycki MB (2008) Enzyme replacement therapy for mucopolysaccharidoses: opinions of patients and families. J Pediatr 152:723-727

6. Connock M, Juarez-Garcia A, Frew E, Mans A, Dretzke J, FrySmith A, Moore D (2006) A systematic review of the clinical effectiveness and cost-effectiveness of enzyme replacement therapies for Fabry's disease and mucopolysaccharidosis type 1. Health Technol Assess 10:iii-iv, ix-113

7. Froissart R, Maire I, Millat G, Cudry S, Birot AM, Bonnet V, Bouton O, Bozon D (1998) Identification of iduronate sulfatase gene alterations in 70 unrelated Hunter patients. Clin Genet 53:362-368

8. Galan-Gomez E, Guerrero-Rico A, Caceres-Marzal C, ZambranoCastano M, Moreno-Tejero ML, Grande-Tejada AM, FernandezHernandez S, Vaquerizo-Madrid J, Cardesa-Garcia JJ (2008) Early response to idursulfase treatment in a 3-year-old boy affected of Hunter syndrome. Eur J Med Genet 51:268-271

9. Glamuzina E, Fettes E, Bainbridge K, Crook V, Finnegan N, Abulhoul L, Vellodi A (2011) Treatment of mucopolysaccharidosis type II (Hunter syndrome) with idursulfase: the relevance of clinical trial end points. J Inherit Metab Dis 34:749-754

10. Goldenfum SL, Young E, Michelakakis H, Tsagarakis S, Winchester B (1996) Mutation analysis in 20 patients with Hunter disease. Hum Mutat 7:76-78

11. Guffon N, Bertrand Y, Forest I, Fouilhoux A, Froissart R (2009) Bone marrow transplantation in children with Hunter syndrome: outcome after 7 to 17 years. J Pediatr 154:733-737

12. Harmatz P, Giugliani R, Schwartz IV, Guffon N, Teles EL, Miranda MC, Wraith JE, Beck M, Arash L, Scarpa M, Ketteridge D, Hopwood JJ, Plecko B, Steiner R, Whitley CB, Kaplan P, Yu ZF, Swiedler SJ, Decker C (2008) Long-term follow-up of endurance and safety outcomes during enzyme replacement therapy for mucopolysaccharidosis VI: final results of three clinical studies of recombinant human $\mathrm{N}$-acetylgalactosamine 4sulfatase. Mol Genet Metab 94:469-475
13. Isogai K, Sukegawa K, Tomatsu S, Fukao T, Song XQ, Yamada Y, Fukuda S, Orii T, Kondo N (1998) Mutation analysis in the iduronate-2-sulphatase gene in 43 Japanese patients with mucopolysaccharidosis type II (Hunter disease). J Inherit Metab Dis 21:60-70

14. Katz R, Burton B (2008) A home infusion protocol for MPS II patients on enzyme replacement therapy (ERT). Mol Genet Metab 93:S25-S26

15. Kishnani PS, Corzo D, Nicolino M, Byrne B, Mandel H, Hwu WL, Leslie N, Levine J, Spencer C, McDonald M, Li J, Dumontier J, Halberthal M, Chien YH, Hopkin R, Vijayaraghavan S, Gruskin D, Bartholomew D, van der Ploeg A, Clancy JP, Parini R, Morin G, Beck M, De la Gastine GS, Jokic M, Thurberg B, Richards S, Bali D, Davison M, Worden MA, Chen YT, Wraith JE (2007) Recombinant human acid [alpha]-glucosidase: major clinical benefits in infantile-onset Pompe disease. Neurology 68:99-109

16. Li P, Bellows AB, Thompson JN (1999) Molecular basis of iduronate-2-sulphatase gene mutations in patients with mucopolysaccharidosis type II (Hunter syndrome). J Med Genet 36:21-27

17. Martin R, Beck M, Eng C, Giugliani R, Harmatz P, Munoz V, Muenzer J (2008) Recognition and diagnosis of mucopolysaccharidosis II (Hunter syndrome). Pediatrics 121:e377-e386

18. McGill J, Sillence D, Ketteridge D, Peters H, Knight G (2008) Guidelines for eligibility to receive treatment for mucopolysaccharidosis type II (MPS-II) with idursulfase through the life saving drugs program. Australian Government Department of Health and Ageing Web site. Available at http://www.health.gov. au/internet/main/publishing.nsf/Content/lsdp-info/\#Idursulfase Accessed 20 April 2011

19. McKinnis EJ, Sulzbacher S, Rutledge JC, Sanders J, Scott CR (1996) Bone marrow transplantation in Hunter syndrome. J Pediatr 129:145-148

20. Milligan A, Hughes D, Goodwin S, Richfield L, Mehta A (2006) Intravenous enzyme replacement therapy: better in home or hospital? Br J Nurs 15:330-333

21. Moore DF, Ries M, Forget EL, Schiffmann R (2007) Enzyme replacement therapy in orphan and ultra-orphan diseases: the limitations of standard economic metrics as exemplified by Fabry-Anderson disease. PharmacoEconomics 25:201-208

22. Moreira da Silva I, Froissart R, Marques dos Santos H, Caseiro C, Maire I, Bozon D (2001) Molecular basis of mucopolysaccharidosis type II in Portugal: identification of four novel mutations. Clin Genet 60:316-318

23. Muenzer J (1986) Mucopolysaccharidoses. Adv Pediatr 33:269-302

24. Muenzer J, Beck M, Eng CM, Escolar ML, Giugliani R, Guffon NH, Harmatz P, Kamin W, Kampmann C, Koseoglu ST, Link B, Martin RA, Molter DW, Munoz Rojas MV, Ogilvie JW, Parini R, Ramaswami U, Scarpa M, Schwartz IV, Wood RE, Wraith E (2009) Multidisciplinary management of Hunter syndrome. Pediatrics 124:e1228-e1239

25. Muenzer J, Wraith JE, Beck M, Giugliani R, Harmatz P, Eng CM, Vellodi A, Martin R, Ramaswami U, Gucsavas-Calikoglu M, Vijayaraghavan S, Wendt S, Puga A, Ulbrich B, Shinawi M, Cleary M, Piper D, Conway AM, Kimura A (2006) A phase II/III clinical study of enzyme replacement therapy with idursulfase in mucopolysaccharidosis II (Hunter syndrome). Genet Med 8:465473

26. Muenzer J, Wraith JE, Clarke LA (2009) Mucopolysaccharidosis I: management and treatment guidelines. Pediatrics 123:19-29

27. Neufeld EF, Muenzer J (2001) The mucopolysaccharidoses. In: Scriver CR, Beaudet AL, Sly WS, Valle D (eds) The metabolic and molecular bases of inherited disease, 8th edn. McGraw-Hill, New York, pp 3421-3452

28. Paras A, Katz R, Burton BK (2007) Challenges of treating patients with Hunter syndrome and CNS disease with enzyme 
replacement therapy (ERT): a case report. ASHG 2007 Meeting Poster Presentation Listings. Available at http://www.ashg.org/ genetics/ashg07s/f20104.htm. Accessed 20 April 2011

29. Prasad VK, Kurtzberg J (2010) Transplant outcomes in mucopolysaccharidoses. Semin Hematol 47:59-69

30. Schlander M, Beck M (2009) Expensive drugs for rare disorders: to treat or not to treat? The case of enzyme replacement therapy for mucopolysaccharidosis VI. Curr Med Res Opin 25:1285-1293

31. Staba SL, Escolar ML, Poe M, Kim Y, Martin PL, Szaboles P, Allison-Thacker J, Wood S, Wenger DA, Rubinstein P, Hopwood JJ, Krivit W, Kurtzberg J (2004) Cord-blood transplants from unrelated donors in patients with Hurler's syndrome. N Engl J Med 350:1960-1969

32. Vafiadaki E, Cooper A, Heptinstall LE, Hatton CE, Thornley M, Wraith JE (1998) Mutation analysis in 57 unrelated patients with MPS II (Hunter's disease). Arch Dis Child 79:237-241

33. van Aerde J, Plets C, Van der Hauwaert L (1981) Hydrocephalus in Hunter syndrome. Acta Paediatr Belg 34:93-96

34. Vellodi A, Wraith JE, Cleary MA, Ramaswami U, Lavery C, Jessop E (2007) Guidelines for the investigation and management of mucopolysaccharidosis type II. National Commissioning Group For Highly Specialised Services Web site. Available at http://www. specialisedservices.nhs.uk/library/23/Guidelines_for_Mucopolysac charidosis_Type_II.pdf Accessed 20 April 2011
35. Vellodi A, Young E, Cooper A, Lidchi V, Winchester B, Wraith JE (1999) Long-term follow-up following bone marrow transplantation for Hunter disease. J Inherit Metab Dis 22:638-648

36. Wraith JE, Beck M, Lane R, van der Ploeg A, Shapiro E, Xue Y, Kakkis ED, Guffon N (2007) Enzyme replacement therapy in patients who have mucopolysaccharidosis I and are younger than 5 years: results of a multinational study of recombinant human alpha-L-iduronidase (laronidase). Pediatrics 120:e37-e46

37. Wraith JE, Scarpa M, Beck M, Bodamer OA, De Meirleir L, Guffon N, Meldgaard Lund A, Malm G, Van der Ploeg AT, Zeman J (2008) Mucopolysaccharidosis type II (Hunter syndrome): a clinical review and recommendations for treatment in the era of enzyme replacement therapy. Eur J Pediatr 167:267-277

38. Yatziv S, Epstein CJ (1977) Hunter syndrome presenting as macrocephaly and hydrocephalus. J Med Genet 14:445-447

39. Young ID, Harper PS (1981) Psychosocial problems in Hunter's syndrome. Child Care Health Dev 7:201-209

40. Young ID, Harper PS (1982) Mild form of Hunter's syndrome: clinical delineation based on 31 cases. Arch Dis Child 57:828-836

41. Young ID, Harper PS (1983) The natural history of the severe form of Hunter's syndrome: a study based on 52 cases. Dev Med Child Neurol 25:481-489

42. Young ID, Harper PS, Newcombe RG, Archer IM (1982) A clinical and genetic study of Hunter's syndrome. 2. Differences between the mild and severe forms. J Med Genet 19:408-411 